\title{
De la utopía al desencanto del 92 en el cine español
}

\author{
José Luis Sánchez Noriega ${ }^{1}$
}

Recibido: 6 de septiembre de 2018 / Aceptado: 7 de septiembre de 2018

Resumen. La alternativa socialista de 1982, que inicia la España de la postransición, otorga un impulso a la modernización del país y un notable crecimiento económico con la integración en Europa, a la vez que defrauda las expectativas de cambio social. Desde el punto de vista sociopolítico, la sociedad española del post-92 experimenta un desencanto del que se va a hacer eco el cine más comprometido y que, con bastante elocuencia, se aprecia en las películas de Mario Camus. En este trabajo se hace balance de los cambios sociales y sucesos relevantes de los gobiernos socialistas (1982-1996) y se indaga en cómo esos filmes los reflejan críticamente, poniendo énfasis en las diferencias sociales, las figuras de perdedores, la impostura y la violencia.

Palabras clave: cine español; gobiernos PSOE; terrorismo; corrupción; Mario Camus

\section{[en] From Utopia to the 92's Disillusionment in Spanish Cinema}

\begin{abstract}
The socialist alternative in 1982, that initiates the post Transition (to democracy) era in Spain, gives an extraordinary impulse to its modernization and a significant economical increase due to the integration within Europe, as it simultaneously lets down the expectations on social change. From a socio-political point of view, the post-92 Spanish society experiments a disappointment echoed in the most committed cinema, and is quite eloquently manifests in Mario Camus' films. In the present article, an evaluation of the social changes and remarkable events from the socialist governments (1982-1996) has been made, while examining how these films critically reflect the social differences, the roles of the losers, the imposture and violence.
\end{abstract}

Keywords: Spanish cinema; PSOE governments; terrorism; corruption; Mario Camus

Sumario. 1. El cambio social de los gobiernos socialistas (1982-1996). 2. El ciclo de Mario Camus de los 90. 3. Diferencias sociales e ideológicas: el afán de dinero. 4. Imposturas, máscaras y mentiras. 5. Sensacionalismo periodístico y manipulación social. 6. Figuras de perdedores o marginados. 7. Ni venganza ni perdón. 8 . El regalo de la pareja y la familia. 9. Bibliografía

Cómo citar: Sánchez Noriega, J.L. (2018) De la utopía al desencanto del 92 en el cine español, en Área Abierta. Revista de comunicación audiovisual y publicitaria 19 (1), 13-27. http://dx.doi.org/10.5209/ ARAB.61447

\footnotetext{
$1 \quad$ Universidad Complutense de Madrid (España)

E-mail: noriega@ucm.es
} 


\section{El cambio social de los gobiernos socialistas (1982-1996)}

Cierto clima de decepción y hasta cierta depresión social a principios de los noventa en nuestro país se debe a la trayectoria vivida por la sociedad española en el decenio anterior, el ciclo de euforia económica y ciudadana a partir de la entrada de España en la entonces Comunidad Económica Europea (1986) y la preparación y culminación con los acontecimientos de fuerte significado político y social -y elevación de la autoestima ciudadana- que confluyen en 1992: la Exposición Universal de Sevilla, los Juegos Olímpicos de Barcelona y el V Centenario del Descubrimiento de América. Téngase en cuenta, además, el entusiasmo electoral con que había llegado el PSOE al poder, con lo que ello supone de clausura de la Transición en cuanto es la primera vez desde la Guerra Civil que la izquierda ostenta el gobierno de la nación ${ }^{2}$.

Las cuatro legislaturas de los gobiernos socialistas (1982-1996) suponen una evolución notable del país en todos los órdenes, de manera que la consolidación de la democracia, la integración en Europa, la reconversión industrial y el crecimiento económico trazan un escenario realmente nuevo en relación con la sociedad y la práctica política del tardofranquismo y la Transición; un escenario no exento de tensiones y contradicciones, la mayor de las cuales es la progresiva decepción de la ciudadanía de izquierdas con mayor fe en una democracia avanzada.

La reacción de la derecha frente a las políticas más abiertas de UCD que llevan directamente a la desaparición del partido que había pilotado la restauración democrática (pasa del 34,8\% de votos en 1979 al 6,7 \% en 1982) y el golpe de Estado militar de 1981 crean el clima ciudadano de apoyo al partido socialista liderado por el carismático Felipe González, que logra en 1982 el 48,4 \% de los votos en las elecciones generales y 202 diputados, una mayoría nunca superada en la democracia española reciente; cuando pierda el poder en 1996, lo hará por un exiguo 1,16\% menos de votos que el Partido Popular, que forma gobierno con 156 diputados, a veinte de la mayoría absoluta.

A lo largo de esos catorce años de gobiernos socialistas el país experimenta una transformación con las infraestructuras (red de autovías, alta velocidad ferroviaria), legislaciones progresistas en sanidad - con la práctica universalización para asalariados y desempleados - y educación, que pasa a ser, en la práctica, obligatoria y gratuita entre los tres y dieciséis años (el gasto educativo se eleva de 0,93 billones en 1984 a 2,6 en 1992; el último cuarto de siglo ve multiplicarse por casi siete el número de universitarios hasta llegar a los dos millones; el de la Seguridad Social se multiplica casi por tres en el decenio anterior a 1992), dotaciones en museos, nuevos centros de arte y equipamientos culturales y deportivos, modernización de la arquitectura pública (fenómeno Calatrava), incremento de bienes de consumo (el número de automóviles crece de nueve a catorce millones entre 1985 y 1992) y de medios

Sirva como resumen de la situación este diagnóstico: "En el seno de Europa, el PSOE no era el único entre los partidos socialdemócratas que se alejaba cada vez más de sus raíces obreras y de la promesa de un capitalismo más suave, pero la traición de sus bases fue especialmente amarga en el caso español. El Partido Socialista español (al igual que el francés) sólo llegó al poder cuando el apogeo de la socialdemocracia había finalizado. Desde la crisis del petróleo de 1973 y la presión cada vez mayor de la competencia mundial, los Estados del Bienestar de la posguerra, que habían pagado las generosas prestaciones sociales con un crecimiento económico en auge, entraron en crisis. En España, el PSOE se enfrentaba a esta crisis en una joven democracia cuyo Estado del Bienestar estaba todavía en pañales. En este contexto, en el que los trabajadores llevaban décadas esperando un Gobierno que representara sus intereses, las políticas económicas neoliberales del PSOE se percibieron como una puñalada en la espalda. (Radcliff, 2018: cap. 7). 
de ocio (vídeo doméstico, turismo), expansión de hipermercados y grandes centros comerciales en los extrarradios de las ciudades, nueva cultura gastronómica y "democratización" del placer culinario con programas de televisión, atención al gusto por el vestir (modistos nuevos, Moda España) y su expansión a las clases populares (Zara), mejora de la vivienda (urbanizaciones con mayores equipamientos y cultura del adosado) y atención a la decoración (Díaz Barrado, 2006: cap. 3), etc. En los diez primeros años de pertenencia a la Unión Europea son patentes las mejoras económicas y sociales, con la excepción de la tasa de desempleo: se reduce en siete puntos el desnivel del PIB respecto a la media europea, en seis el capital humano con estudios superiores, en doce la diferencia de stock de capital tecnológico, y en 7,5 los gastos en protección social (Soto Carmona, 2005: 281). Las transformaciones llevan a una estratificación social propia del neocapitalismo donde la sociedad crecientemente urbana, la pujanza del sector terciario y la industrialización conforman a una amplia clase media donde se autositúa la mayoría de la población.

Al filo de 1992, España consigue una presencia internacional sin antecedentes en su historia reciente: se celebra en Madrid la Conferencia sobre Paz en Oriente Próximo, a la que acuden los líderes mundiales; los Juegos Olímpicos suponen una inversión de 4800 millones de euros y constituyen un éxito de imagen, incluso para el propio país, que multiplica por ocho las cuatro medallas conseguidas en las anteriores olimpiadas; la Expo sevillana logra dieciocho millones de visitantes, pero, sobre todo, la nueva línea de alta velocidad Madrid-Sevilla supone el inicio de una costosa inversión de 2700 millones que cambia el panorama de las infraestructuras de transporte; Madrid es designada como Capital Europea de la Cultura; y, en su segunda edición, nuestro país es anfitrión de la Cumbre Iberoamericana de Jefes de Estado y de Gobierno, lo que va a potenciar su apertura exterior y una nueva imagen

Como un país moderno, definitivamente alejado del estereotipo romántico (de charanga, pandereta, bandoleros y toreros) y, sobre todo, como país puente entre la Unión Europea, a la que pertenecía desde 1986, y el conjunto de Latinoamérica, borrando así de forma definitiva los restos del paternalismo de la Hispanoamérica del franquismo, por las más igualitarias relaciones establecidas tras la restauración de la democracia (Ruiz, 2002: 104).

La participación de las Fuerzas Armadas en misiones de paz y acciones humanitarias (entre 1988 y 1996 en diez países de tres continentes) bajo bandera de las Naciones Unidas no solo proporciona al Ejército una nueva dimensión e imagen pública, que le permite superar el síndrome del golpismo post- $23 \mathrm{~F}$, sino que afianza su estatuto en democracia y logra un reconocimiento ciudadano impensable unos años antes.

Esta situación no es incompatible con tensiones sociales y políticas (referendum OTAN), sobre todo por una política de austeridad y una reconversión industrial (minero-siderurgia, astilleros) en la primera etapa de los gobiernos socialistas que lleva a la huelga general del 14-D de 1988, un paro inusitado en la historia del país donde también se escenifica la ruptura entre el partido socialista y UGT, su sindicato "hermano". Los prometidos 800.000 puestos de trabajo que figuran en el programa electoral con el que el PSOE llega al poder no solo no se alcanzan, sino que se convierten en otros tantos parados, cuando la tasa de desempleo pasa del 16,2 al 21,3\% durante esa primera legislatura (1982-1986). A partir de esta última fecha se inicia 
un ciclo de crecimiento - impulsado, en buena parte, por los fondos europeos - que permite combatir el desempleo; pero lo decisivo en ese momento es, al hilo de una política neoliberal y neocapitalista, la expansión de la cultura del pelotazo y de una economía cortoplacista que favoreció la inversión especulativa y el enriquecimiento rápido. En abierta contradicción con la tradición socialista, "se cuestionaron como anacrónicos el ahorro y el rechazo de la ostentación” (Ruiz, 2002: 88) y se erigieron en modelo de éxito meteóricas carreras financieras como las de Mario Conde, los Albertos (Cortina y Alcocer) o Javier de la Rosa, que al cabo del tiempo demostraron ser manifiestamente fraudulentas, o figuras de la beautiful people luego implicadas en delitos económicos como Manuel de la Concha y el gobernador del Banco de España Mariano Rubio (caso Ibercorp). La destitución de Mario Conde, presidente del Banesto - uno de los siete mayores bancos del país - y la intervención estatal del propio banco en 1993 supone para muchos ciudadanos una decepción moral profunda, si se tiene en cuenta que ese mismo año el banquero es investido doctor honoris causa por la principal universidad española en presencia del $\mathrm{Rey}^{3}$ e imparte una conferencia sobre ética de los negocios en el mismo Vaticano.

La corrupción política, en casos de diversa entidad e implicación, surge del centro mismo del poder con la financiación ilegal del PSOE (caso Filesa), el tráfico de influencias de Juan Guerra que lleva la destitución del vicepresidente Alfonso Guerra en 1991 y a la división del partido, las “escuchas del CESID”, el expolio de Luis Roldán, director de la Guardia Civil, que se llevó treinta millones de euros antes de fugarse, las mordidas obtenidas por el presidente navarro Gabriel Urralburu, etc. Pero los crímenes económicos palidecen en relación con los crímenes de la "guerra sucia" de los GAL (Grupos Antiterroristas de Liberación), que alcanzan al mismo Gobierno, en la persona del ministro de Interior y de la cúpula policial. Entre 1983 y 1987, los GAL cometen veintisiete asesinatos contra militantes o simpatizantes de etarras, aunque la justicia no logra probar la implicación del ministro Barrionuevo más que en el secuestro de Segundo Marey, confundido con un dirigente de la organización terrorista. A esto se suma el caso Lasa y Zabala, que condena, años después, a un coronel y a un gobernador civil por el secuestro y asesinato en 1983 de dos presuntos militantes de ETA.

También resulta relevante señalar que, además de los atentados y asesinatos de policías y guardias civiles, políticos y militares considerados como enemigos del pueblo vasco por la organización terrorista ${ }^{4}$, ésta muestra su crueldad y contradicción con el asesinato de sus disidentes: en 1976, en el proceso de pacificación que supuso la renuncia a las armas de ETA (p-m), desaparece Eduardo Moreno Bergareche (Pertur); un decenio después, Dolores González Katarain (Yoyes), que había llegado a pertenecer al comité ejecutivo de ETA en los setenta y abandona la organización, tras su vuelta de México y Francia donde residió el primer lustro de los ochenta, será asesinada en Ordicia delante de su hijo de tres años en plena calle (De Pablo, 2017: 279), suceso plasmado en el filme Yoyes (Helena Taberna, 2000). Para la filmografía

3 Tuvo lugar el 9 de junio de 1993 en la Universidad Complutense siendo rector Gustavo Villapalos; tras las condenas diversas del banquero, se revocó ese nombramiento en 2016.

4 Del total estimado en 854 víctimas en toda la historia de ETA (1968-2011), la mitad correspondería a los años de los gobiernos socialistas, con una distribución muy desigual, pero que no alcanza las cifras de la Transición (65 muertos en 1978, 77 en 1979 y 95 al año siguiente), aunque tienen lugar los atentados más sangrientos: 12 guardias civiles asesinados por un coche bomba en Madrid en 1986 y 21 muertos y 45 heridos del atentado indiscriminado a Hipercor en Barcelona en 1987 (El País, 4-5-2018). 
en la que vamos a profundizar hay que recordar el secuestro y asesinato del ingeniero de la central nuclear de Lemóniz José María Ryan en 1981. Lemóniz —que nunca llegó a funcionar como central y actualmente se estudia su transformación en piscifactoría - fue objetivo político de ETA que atentó en cuatro ocasiones: en marzo de 1978 una bomba mató a dos operarios e hirió a catorce, en junio de 1979 otro explosivo causaba la muerte de una persona, en enero de 1981 fue asesinado Ryan y un año después Ángel Pascual Múgica, ingeniero responsable de proyectos de la nuclear.

Este clima de corrupción resulta especialmente escandaloso porque el PSOE 1lega al poder "declarando sus cien años de honradez y del deseo de trasladar a la vida pública española un sentido ético y una práctica honesta" (Díaz Barrado, 2006: 258), aunque ciertamente no toda la corrupción viene del partido socialista y el yuppismo y el culto al dinero constituye, más allá del caso español, un fenómeno mundial en los ochenta y noventa. Lo cierto es que el proceso de modernización económica y social, con notables logros en sanidad y educación, y expansión de la clase media, coexiste con un deterioro del músculo moral de la sociedad, que se plasma en el abandono de los ideales de solidaridad, austeridad, conciencia de clase, denuncia de desigualdades, internacionalismo, etc. de la tradición de la izquierda. En fin, "La España del comienzo de la Transición quería ser roja, en lenguaje de la época, para recuperar el tiempo perdido en su historia trágica y superar de una vez esa España negra y terrible, pasó a ser la España rosa del cotilleo y la fascinación por el dinero y el disfrute material" (Díaz Barrado, 2006: 261).

\section{El ciclo de Mario Camus de los noventa}

No pretendemos establecer una causalidad directa entre el talante moral de la sociedad y el clima social y político de esos años de presidencia de Felipe González, y las películas de Mario Camus coetáneas, pues en este cineasta no hay voluntad de crónica de la realidad inmediata ni en su carrera figuran filmes de formato "basado en hechos reales". Esta aseveración no contradice la apreciación en las ficciones de ciertas sintonías, ecos o convergencias con sucesos, motivaciones, estilos, etc. de la sociedad española del felipismo. Ello tiene lugar con guiones propios, así como con adaptaciones de novelas tanto coetáneas (Miguel Delibes, Juan Luis Cebrián, Félix Bayón) como escritas décadas atrás (La forja de un rebelde, 1990). Además, el ciclo de los noventa presenta en el cineasta una obra más personal, con varios guiones en solitario y una voluntad autoral inequívoca como manifiestan los créditos "Una historia escrita para el cine por Mario Camus" repetidos en Después del sueño (1992) y Sombras en una batalla (1993). La inserción de la ficción de esta última en el contexto específico queda clara en estas palabras de presentación de la película por parte del cineasta "En este país, desde el final de la dictadura, hace ya casi 20 años, están pasando cosas muy determinadas, entre ellas el terrorismo. Yo no sé si mi película es valiente o si es que el cine español está adormecido, pero, ahora que hay libertad, ¿por qué no voy a atreverme a hablar del terrorismo de mi país?” (Muñoz, 1993).

Tampoco es que los rodajes durante los gobiernos socialistas supongan un hito en la carrera del cineasta o configuren un ciclo por sí mismos; todas las películas de este período tienen diversas conexiones directas con temas, preocupaciones e intereses que aparecen como constantes de la identidad autoral de Mario Camus. Incluso cier- 
tas historias muy ancladas en sucesos reales del período (La rusa [1987], Sombras en una batalla y, más tarde, La playa de los galgos [2002]) trascienden sus temas específicos para abundar en transversales del conjunto de la filmografía como son la redención del pasado, la impostura que imposibilita las relaciones sentimentales, la dificultad para el perdón y la superación de la venganza, etc. La filmografía del director cántabro entre 1982 y 1996 cuenta también con obras más intemporales ( $L a$ vieja música, 1985; La casa de Bernarda Alba, 1987), aunque los temas de fondo presentan algunos anclajes con la actualidad. En el caso de La colmena (1982), forma parte del amplio ciclo que el cine español de la Transición dedica a la revisión de la historia inmediata de España, como hemos expuesto en otro lugar (Sánchez Noriega, 2014: 56-66), revisión que también sirve para plantear reivindicaciones y valores en el proceso de construcción de la democracia. En esa misma perspectiva hay que situar Los santos inocentes (1984) que, si bien no puede considerarse cine histórico, constituye una radiografía de las clases sociales durante el franquismo y se estrena en pleno cambio político.

La figura de Arturo Barea - central en la serie de seis capítulos de noventa minutos La forja de un rebelde - es para una generación antifranquista un modelo de lucha por la vida, compromiso con la educación y la cultura de la "república de las letras" y militante demócrata en las tensiones de los años treinta que abocan a la guerra. Pero también esa vida constituye un fresco o crónica de buena parte de la historia, conflictos sociales, diferencias de clase, militarismo, etc. de la España del primer tercio de siglo, al tiempo que plasma los valores morales, cívicos, educativos y políticos que han de ser de referencia para la sensibilidad de la izquierda en los ochenta y noventa. Nos referimos a cuestiones como el valor del saber, los libros y la educación, la dureza y dignidad del trabajo, la toma de conciencia y el compromiso de lucha, la hipocresía del mundo del dinero, el sentido de pertenencia a la clase trabajadora, la alianza con los ricos del catolicismo; todo ello en un contexto social e histórico donde Barea experimenta en carne propia la explotación laboral, las profundas desigualdades y la corrupción de los gobernantes. Por tanto, Arturo Barea aparece como un modelo de la moral de izquierda y La forja de un rebelde es el relato marco de la filmografía de Camus de estos años, en el sentido de que se presenta como un epítome o mapa donde se cartografían los temas de fondo y los valores que, situados medio siglo atrás, siguen vigentes en cuanto conformadores de la utopía democrática e igualitaria que la izquierda intenta plasmar durante la II República y que, con el acceso del PSOE al poder en 1982, se toma como referencia de algún modo.

\section{Diferencias sociales e ideológicas: el afán de dinero}

Ya en Los pájaros de Baden-Baden (1974) se explicitaba el diagnóstico de los mundos irreconciliables, burgués y popular, con las diferencias sociales e ideológicas que se categorizan entre opresores y oprimidos, adinerados y asalariados, y una crítica a los valores, ideología y modos de vida de la burguesía conservadora (Sánchez Noriega, 1998: 198-200). Esas diferencias —más marcadas al tratarse de otro contexto histórico - aparecen muy explícitas en La forja de un rebelde. Las socioeconómicas también son diferencias culturales e ideológicas, de manera que se configuran esas dos cosmovisiones contrapuestas. 
El poder opresivo y dañino aparece vinculado al dinero; es decir, se trata del poder económico que se explicita en el poder de los banqueros en Amor propio (1994). Esta película está inspirada en un suceso real: en diciembre de 1991, José Pérez Díaz, director de la sucursal uno de Santander del Banco Popular, conocido como "Pepe el del Popular", desapareció con una cantidad en torno a los treinta y tres millones de euros. Había creado un banco paralelo en el que ofrecía intereses de hasta el catorce y el quince por ciento, muy por encima de la media del sector, y en el que manejó unos cuarenta y dos millones, de los cuales se calcula que más de seis eran de dinero negro. Se trata de un hecho real muy concreto, pero tiene valor metonímico en cuanto, como queda señalado más arriba, escándalos de mayor envergadura (Mario Conde, Ibercorp) revelan una implicación directa de la banca en prácticas ilegales; de hecho, el cineasta se inspira en la figura de Mario Conde cuando, en un diálogo, dos ejecutivos comentan que al presidente del banco le habían hecho doctor honoris causa (Sánchez Noriega, 1998: 332). En boca del presidente del Banco Continental del Norte se resume la perspectiva del cineasta: "Somos los guardianes del Estado de Bienestar. Creamos riqueza y nuestra responsabilidad nos impide cualquier tentación humanitaria. Nos hemos enriquecido practicando la usura, no hay por qué ocultarlo (...) Nadie nos va a robar nuestro prestigio y, no es por nada, sino porque de ese prestigio nos vienen los caudales, que decía mi abuelo". Sin embargo, además de la usura $-\mathrm{y}$ de la praxis ilegal ofreciendo intereses desmedidos, como demuestra la carta que el banquero quiere recuperar - hay un comportamiento mafioso en el secuestro de Simón por parte de los directivos del banco, que quieren destruir toda prueba que les inculpe y recuperar el dinero estafado.

Que el valor del dinero es el dominante en la sociedad ${ }^{5}$ queda ratificado en otro diálogo, esta vez en boca de Quico Jiménez, un gitano que compra "todo lo que se venda, hasta el alma si la dan barata, que hoy es un género que tiene muy poca salida". También en esta película aparece un personaje representativo de la beautiful people de la época, especuladores e intermediarios sin profesión específica pero dispuestos a ganar dinero fácil, elementos centrales en la cultura del pelotazo. Es Enrique (Antonio Resines), de inequívoco look con gomina en el pelo, el hermano de la protagonista que vive del dinero de su hija y se ofrece a intermediar con los banqueros; una figura que recuerda al "trepa" protagonista de Huevos de oro (Bigas Luna, 1993). También el contexto histórico de la reconversión de la industria agropecuaria - y la exigente reducción de la cuota lechera de la Unión Europea- está presente en El prado de las estrellas (2007), con ganaderos escépticos ante su futuro cuando un funcionario les plantea cambios radicales en su modo de vida.

Aunque se trate de una referencia más episódica, el cuadro de Picasso robado a un viejo militante comunista acaba en manos de un presidente de banco en Después del sueño, que obviamente lo ha adquirido de forma ilegal, lo que parece preludiar el suceso del banquero Jaime Botín, acusado en 2015 de exportar ilegalmente un lienzo de Picasso cuando la policía francesa encontró la pintura en su barco fondeado en Córcega. En esta película también se trazan claramente las diferencias socioeconómicas e ideológicas y morales entre los poderosos o ambiciosos próximos a los

Díaz Barrado (2006: 118) hace hincapié en el cambio que se ha producido al respecto en estos años: "todavía a mediados de los años setenta, la aspiración a otros empleos mejores mezclaba siempre los aspectos económicos con la consideración social (...) Más tarde, la remuneración económica pasará a convertirse en lo más importante, se prescindirá de la consideración moral o social de los empleos y, en algunos casos, sin importar mucho que estuvieran al borde de la ilegalidad" (subrayado nuestro). 
círculos del poder (Anselmo y Ángeles, Sempere, periodista) y quienes, como Amós o Antonio Blasco, se sitúan en otra órbita.

En El color de las nubes (1997) aparece también el dinero como causa de los conflictos, tanto criminales (tráfico de drogas y delincuencia asociada) como legalesmorales, como el intento de desahucio de la protagonista Lola por parte del heredero de la casa en que vive, y cuyo usufructo vitalicio le otorgó el amor de su vida. Ese heredero, que no ha respetado la voluntad de su padre y carece de toda empatía hacia la anciana, muestra el estilo del poder en sus relaciones, como se aprecia en el diálogo que mantiene con Valerio, cuando este pone reparos al desahucio, a quien ordena "Eres abogado y estás a mi servicio. Yo soy quien te paga y harás aquello que te mande sin decir palabra. Eso es todo."

Igualmente, la crítica al enriquecimiento fácil aparece en El prado de las estrellas donde, cuando Nanda se queja de que a sus hijos sólo les interesan las propiedades que heredarán, Alfonso explica "Hoy en día la gente no se anda con pamplinas. Se trata de dinero y eso lo entienden bien. Todos esos mandrias viven de la usura y hacen fortunas engañando al personal y cobrando intereses eternos." Más tarde, cuando los abogados de los hijos tratan de impugnar el testamento o de negociar la propiedad del prado de las estrellas dejado en herencia, el de Alfonso rechaza toda componenda.

Frente a la ambición del dinero y a las prácticas especulativas se apuesta por el valor del esfuerzo y el aprecio del trabajo en el desarrollo de una profesión con entrega personal. Esto se afirma en El prado de las estrellas mediante la caracterización de personajes vinculados a su trabajo/profesión a través de los diálogos o de los conflictos que surgen: Mauri y los problemas de supervivencia de los ganaderos y agricultores, Luisa y su dedicación a los ancianos, Ramiro y el taller de viejas motos reconstruidas, el joven Martín y la dedicación al ciclismo. En este último caso, junto a ese esfuerzo se subraya el aprendizaje, tanto en la práctica del deporte - que viene a ser metáfora de la vida y de la relación con los demás - como por el valor de mantener viva la curiosidad, adquirir una cultura y hasta por el propio gusto por saber, incluso cuando carezca de una utilidad inmediata, como verbaliza el profesor Escobedo.

\section{Imposturas, máscaras y mentiras}

La mentira, la trampa, la manipulación, las máscaras o la impostura; es decir, las diversas formas de falsedad y engaño, son los mecanismos privilegiados para perpetuar las desigualdades sociales o mantener la dominación de unas clases sobre otras. Asimismo, como se indica más adelante, la mentira o el engaño corroen los cimientos de las relaciones de pareja, que terminan en la disolución o en la fosilización hipócrita.

La España de la sociedad de consumo a que ha llevado la entrada en la Unión Europea y el ciclo de crecimiento subsiguiente, ve proliferar urbanizaciones de viviendas unifamiliares en el extrarradio de las grandes ciudades destinadas a las nuevas clases medias o de trabajadores cualificados, buena parte de ellas promovidas en régimen de cooperativa por sindicatos. Adosados (1996) traslada la novela homónima de Félix Bayón que tematiza la hipocresía y las inseguridades de esas nuevas clases sociales; debajo de la ordenada vida del chalet adosado en urbanizaciones 
con centros comerciales y equipamientos deportivos hay una gran fragilidad ante lo inesperado. El director subraya que los personajes "están metidos en la sociedad del bienestar cuyo modo de vivir absolutamente perfecto nadie puede atacar. Entonces hay una fisura y por ella entran las hormigas que desencadenan un proceso de angustia inesperado e incontrolable" (El País, 1-9-1996) ${ }^{6}$.

La centralidad del tema de la falsedad o la mentira en la película es tal que el desarrollo dramático parece una sistemática ejemplificación de situaciones y funciones en que se miente: 1) la joven que engaña en su conversación a través del móvil; 2) el sacrificio y enterramiento del perro; 3) el amante que tiene Paula; 4) las chicas que hacen encuestas en la calle; 5) el informe de la auditoría donde trabaja Andrés; 6) el despliegue de carteles buscando el perro; 7) las relaciones sexuales de los protagonistas; y 8) la adolescente que se oculta para ser dada por desaparecida y salir en televisión.

Estas mentiras tienen que ver con el miedo a perder la (falsa) seguridad que proporcionan las máscaras y con la manipulación para conseguir unos resultados, como cuando las mentiras son "instrumento" de trabajo en las chicas encuestadoras o los ejecutivos de la auditora "maquillan" sus informes, siguiendo las pautas del jefe: "La auditoría ha de reflejar la verdad, eso está claro. Pero no una verdad cruda, conviene que la elaboremos, que la cocinemos un poco; al fin y al cabo, la verdad es un misterio". En el caso de la pareja, la mentira es, muy señaladamente, el síntoma o la causa de su desmoronamiento - con ruptura o, sin ella, instalada en la falsedad de las relaciones - pues, como explica Paula a su amante para justificar que no va a seguir viéndolo "Es por lo de nuestro pacto: ya sabes, ser coherentes, no mentir, decir siempre la verdad, los cimientos de nuestra relación". Por tanto, hay un diagnóstico sobre la debilidad moral de la sociedad que manipula la verdad, sobre los individuos que tienen miedo a perder su estatus y sobre las relaciones sentimentales y sexuales que se resquebrajan por los engaños. Al final, el resultado es una sociedad muy herida, sin el ideal clásico que enuncia el amante de Paula: "En la antigua Persia decir mentiras era cosa de esclavos; era inconcebible que un ciudadano se atreviera a faltar a la verdad".

El instrumento de esas falsedades es la palabra engañosa o el silencio que oculta la realidad, por tanto, la mentira tiene como consecuencia la (in)comunicación y la soledad, pues lleva al protagonista al silencio, que es un modo de preservarse de todo juicio. Paradójicamente, cuando hay más sinceridad en Andrés es en las conversaciones que mantiene con el inmigrante ruso, cada uno en su idioma, desconociendo el del interlocutor, en unos diálogos que se limitan al gesto o a la empatía por mostrarse las fotos familiares; pero esta interrelación de limitada comunicación deviene auténtica terapia mediante la verbalización del conflicto.

\section{Sensacionalismo periodístico y manipulación social}

El periodismo aparece reflejado críticamente, haciéndose hincapié en la capacidad de los medios para manipular la opinión pública, provocar escándalos o conseguir determinados comportamientos políticos. Aunque el personaje es positivo en tanto

6 Isolina Ballesteros (2001: 278) hablará de simulacros de 'familia unida' que "se ubican en el chalet unifamiliar o adosado de las pseudocomunidades periféricas de la ciudad global, para exponer la incomunicación, la soledad y la desintegración familiar ocultas tras la fachada del bienestar económico y aislamiento "residencial"". 
que apoya la democratización del sistema, el periodista que aparece en La rusa colabora con el protagonista Juan Altamirano y le da información relevante, aunque éste lo maneja al sugerirle que no lo publique porque puede ser una trampa. En otros casos, aparece la figura del periodista sensacionalista o de informadores que viven de los escándalos, como sucede en Amor propio, Adosados y El color de las nubes.

En el caso de Después del sueño, el abogado Antonio Blasco usa a un periodista para que publique la historia del robo de un cuadro de Picasso y, de ese modo, valerse del reportaje como amenaza para los ladrones. El periodista se muestra cínico y maniobrero: "Puedo escribir como me lo proponga y lo que me proponga" y "La historia es buena, no hay que cogérsela con papel de fumar (...) Implicar a los culpables con el poder, aunque sea de una manera indirecta, tampoco estaría mal". Más tarde, en lugar de publicar el reportaje, el periodista alerta a Ángeles, que estaba implicada en el robo, con lo que esa figura aparece como especulador más interesado en la información como mercancía que en el derecho de los ciudadanos a estar informados.

La débil Juana de Amor propio utiliza la publicidad que otorgan los medios para dar a conocer la detención de Simón y la implicación de los dueños del banco. En Adosados se muestra la explotación mediática de sucesos llamativos como la desaparición de una niña, de lo que son responsables los periodistas con sus juicios paralelos, pero también la gente común que busca notoriedad saliendo en la televisión. Una crítica a esa televisión sensacionalista se reitera en El color de las nubes, donde un programa de búsqueda de personas desaparecidas utiliza la manipulación que supone la "puesta en escena" en un reportaje al pedir la realizadora a la madre y al niño que repitan su encuentro para volverlo a filmar.

\section{Figuras de perdedores o marginados}

La figura del perdedor es central en toda la filmografía de Camus hasta el punto de constituir uno de sus rasgos estéticos, como hacía ver, entre otros, Juan Carlos Frugone y como hemos desarrollado en otro lugar (Sánchez Noriega, 1997: 833-837). En los años noventa esta figura adquiere dos identidades precisas: las víctimas de la violencia y los ancianos. En el primer caso se sitúan tanto los vencidos y exiliados políticos (Barea en La forja de un rebelde, Roces y Antonio Lanza en Después del sueño, Dubbini en La playa de los galgos) como los terroristas de ETA y GAL o sus víctimas (Ana y José de Sombras en una batalla, Pablo y Berta de La playa de los galgos).

Resulta novedoso en el último tramo de la filmografía de Camus los personajes de ancianos sometidos a chantajes y vejaciones, como el viejo comunista Roces de Después del sueño, que ha tenido que esconderse cuando le ha sido robado un valioso cuadro que pertenecía a su amigo Antonio Lanza, que regresa del exilio en la Unión Soviética; y Lola (El color de las nubes) o Alfonso (El prado de las estrellas) que se sobreponen a las amenazas.

Un tratamiento más esperanzado, próximo a la narración con ribetes de fábula ejemplar, se encuentra en Amor propio, con el anciano tío de Juana que urde un engaño para quedarse con el dinero estafado; y también en El color de las nubes donde la protagonista Lola en colaboración con el marinero Colo reaccionan con inteligencia y determinación ante las amenazas que, de cumplirse, llevarían a la marginación a la primera. Estos dos ancianos se valen del ingenio y la suerte -por casualidad Colo 
avista fardos de droga en la costa - frente al poder de la pura fuerza o de la propiedad y el dinero; pero lo más importante es que su motivación es netamente la generosidad y el bien de los demás: Lola acoge a un niño huérfano de guerra y Colo impide el desahucio de Lola. En esta película aparecen como perdedores los niños, quienes emergen en el relato como dos seres asustados por su fragilidad e incertidumbre, pero, al mismo tiempo, muestran vocación de supervivencia. No por casualidad, esos niños mantienen con los ancianos una relación de afectividad y de dialéctica maestro/discípulo, carente de todo paternalismo y conmiseración.

Al igual que los citados Lola y Colo, otros ancianos disfrutan con el bien de los demás y tienen un comportamiento presidido por la generosidad: Alfonso y Tasio (El prado de las estrellas) quieren que el ciclista Martín, apenas un adolescente con la familia lejos, desarrolle su vocación deportiva y potencian su voluntad de esfuerzo. Estos cuatro ancianos manifiestan, con palabras o con hechos, el valor del aprendizaje y la educación, y encuentran satisfacción en unas relaciones maestro/ discípulo caracterizadas por la proximidad, el cariño, la paciencia y la comprensión. Los ancianos ven sus vidas gratificadas cuando los niños o jóvenes son receptivos a sus enseñanzas y crecen con ellos.

\section{Ni venganza ni perdón}

Los otros perdedores son las víctimas de los terrorismos. En el cine de Mario Camus se desechan por completo los tratamientos espectaculares de la violencia y tampoco se insertan secuencias violentas como mecanismos de intriga dramática; manifiestamente se renuncia al cine de género o a ciclos (policíaco, bélico, delincuencia juvenil, terror...) donde la violencia constituye un componente imprescindible y se sobrepone a los personajes como recurso para buscar audiencia. En consecuencia, la violencia en sus películas obedece a experiencias reales e históricas, con sucesos guionizados a partir de una documentación contrastada, muy significativas en el contexto actual y reveladoras de algún rasgo caracterizador de nuestra sociedad.

En el tramo de su carrera que venimos considerando hay tres películas esenciales que abordan el terrorismo en nuestro país y lo hacen con el realismo de reflexionar sobre las causas y las consecuencias para las víctimas y verdugos. Pero, lo que es más importante, su anclaje en las distintas dimensiones e implicaciones del terrorismo de ETA en la España de esos años permite a estas ficciones audiovisuales una reflexión muy completa en el sentido de atender a las diversas facetas de la realidad. Veamos con mayor detenimiento estas dimensiones:

1. A pesar de sus motivaciones, el terrorismo etarra ha alimentado las reacciones de la extrema derecha y el peso de los "poderes fácticos" opuestos a la restauración de la democracia. Así aparece en La rusa, cuando unos pistoleros eliminan a un etarra utilizando como cebo a Juan Altamirano, un alto cargo del gobierno enviado a Bruselas para negociar con ETA, con lo que se desbarata una pacificación que sirva para consolidar el sistema de libertades.

2. En el argumento de esa película quedan documentados los contactos entre el Gobierno y la cúpula de la banda ETA en orden a unas posibles negociaciones, contactos que fueron discretos cuando no secretos. Aunque La rusa está ambientada en la Transición, durante los gobiernos de UCD (1977-1982), en 
este punto concreto se refiere, en realidad, a unos primeros contactos en Andorra en 1984 entre el comandante de la Guardia Civil Rodríguez Galingo y el dirigente Domingo Iturbe Abasolo "Txomin"7; y preludia las conversaciones de Argel (1987-1989), que suelen citarse como primer contacto debido a la publicidad que alcanzaron y a la primera tregua de ETA (enero-marzo de 1989) (De Pablo 217: 237).

3. Acciones como la recreada en La rusa acaban por dar lugar a la reacción antiterrorista de los grupos parapoliciales, como aparece también en Sombras en una batalla, con el personaje del portugués José y de los dos policías no identificados que lo buscan, pertenecientes a los GAL alentados desde la cúpula policial.

4. Las organizaciones terroristas evitan cualquier disidencia hasta el punto de asesinar a sus propios militantes, con una dinámica de degradación moral que deslegitima su presunta lucha política. Ello se plantea tanto respecto a los GAL como respecto a ETA en Sombras en una batalla, donde José es perseguido por el etarra - al que reconoce la protagonista Ana y que lo asesina - y por posibles policías miembros de los GAL. Pero hay que interpretar que los etarras estaban buscando a Ana - que ha abandonado la lucha armada y ha puesto tierra de por medio - con el propósito de asesinarla, en un caso similar al de Yoyes (vid. supra). También se hace referencia en esta cinta al caso Pertur, citado más arriba, a quien se dedica la película en un rótulo inicial "A Eduardo"; el director contó con la asesoría de un hermano de Pertur a la hora de escribir el guion (Sánchez Noriega, 1998: 291). Asimismo, Pablo (La playa de los galgos) sufre la pesadilla de que miembros de ETA van en su búsqueda para eliminarlo.

5. La violencia produce daños psicológicos en quienes la ejercen: Pablo y Ana en estas dos películas que, además, sufren el desarraigo y el extrañamiento de la nueva condición de exiliados en que se han convertido por su condición de verdugos $^{8}$. En otras víctimas, como la niña de La playa de los galgos que vivió el asesinato de su madre en la dictadura militar argentina, se subraya el largo y doloroso camino para cauterizar las heridas de la violencia.

6. La venganza acaba sumiendo la violencia en una espiral de terror. El atentado que sufre Juan (La rusa) parece responder a una venganza por su denuncia del atropello de un etarra en Bruselas. La opción por la venganza en Berta ( $L a$ playa de los galgos) deviene en una degradación que la lleva a la autodestrucción; Dubbini ya le había advertido cuando se percata de su intención de asesinar al verdugo de su marido. Él mismo tenía los mismos argumentos de Berta y, sin embargo, renuncia a la venganza. Similar renuncia hay en Ana (Sombras en una batalla), que encañona a los asesinos de José - y, quizá, sus propios verdugos - y ha intentado evitar la muerte de quien podía ser considerado su enemigo. El rótulo conclusivo de esta película refleja la perspectiva moral que el director considera como única legítima ante la violencia terrorista: "Yo no hablo de venganza ni de perdones: el olvido es la única venganza y el único perdón (J.L.B.) [Jorge Luis Borges, Fragmentos de un evangelio apócrifo]"

Así lo recogen José María de Irujo y Ricardo Arqués en el libro ETA, la derrota de las armas (Barcelona: Actualidad y Libros, 1993) citado en Quílez (s.f.).

8 El exilio y desarraigo ya suponía un notable deterioro personal en la figura de Martín, protagonista del filme de Camus La vieja música (1985), donde se profundiza en las heridas personales y sentimentales provocadas por la huida. 
En definitiva, la tesis de fondo tiene un fuerte contenido humanista al considerar de forma prioritaria y al margen de toda estrategia o cálculo político los efectos de la violencia sobre las personas. Ello queda verbalizado por el personaje del psiquiatra argentino Dubbini que, en La playa de los galgos, resume: "La violencia no satisface a nadie: ni al que la padece y sobrevive ni al que la practica porque no sabe cómo parar. Pasa la violencia y sólo quedan desechos humanos, Berta: gente dolorida y rota, a la que le es inaguantable seguir viviendo". Hay que subrayar que este diagnóstico lo enuncia un personaje ajeno a la trama principal de la violencia etarra — es decir, con la suficiente distancia como para un juicio ponderado- pero, al mismo tiempo, se trata de alguien con una vivencia personal muy fuerte, pues su esposa y su hija han sido víctimas de la violencia. El propio cineasta ha explicitado esta tesis en diversos momentos (Sánchez Noriega, 2007: 173).

\section{El regalo de la pareja y la familia}

Las relaciones de pareja y la convención de las historias de amor en la cinematografía clásica adquieren una perspectiva bastante particular en el último Mario Camus. Renuente a los convencionalismos de la narrativa clásica de Hollywood (Bordwell), evita el romance, pero no la constitución de la pareja como logro del equilibrio sentimental o de cierto ideal de felicidad. En el cine y en la novela, la clausura de los relatos revela una visión del mundo respecto a los conflictos planteados por la narración, por lo que las distintas posibilidades de las relaciones de pareja resultan especialmente significativas.

En tres filmes se constituyen parejas desde el encuentro azaroso: los personajes son convocados por un conflicto ajeno en el que colaboran y su amor surge de forma espontánea, sin una voluntad previa, de manera que la felicidad de la pareja se presenta como un regalo. Así le sucede al solitario Amós (Después del sueño) cuyos intereses por encontrar el cuadro robado convergen con los de la enigmática Salud; de igual modo, los estafados Juana e Hilario (Amor propio) colaboran para recuperar su dinero y dignidad, logrando el amor como un plus; una situación muy similar es la de Tina y Valerio (El color de las nubes), que se comprometen para evitar el desahucio de la anciana Lola. Por el contrario, las parejas basadas en el engaño o la infidelidad, o por intereses materiales, están abocadas al fracaso, como en la relación de Ángeles y Antonio (Después del sueño) o de Simón y Maribel (Amor propio); o su continuidad se basa en un juego hipócrita (Adosados).

Resulta significativo que en las dos películas con trasfondo del terrorismo tenga lugar una historia de amor imposible cuando un personaje se enamora de su enemigo. En Sombras en una batalla Ana se ve seducida por José ignorando su pasado de verdugo de los etarras: rompe de inmediato la relación, pero es generosa al avisarle de la amenaza que pesa sobre él. La honestidad de Ana recibe la gratificación del amor con la relación ulterior con Darío, un colega con quien comparte su afición por la naturaleza, muy cercano y cariñoso con su hija ("Blanca me alegra la vida"). La situación de Martín en La playa de los galgos resulta más paradójica: se convierte en cebo con el que Berta espera vengar el asesinato por ETA de su esposo9. El perdón

9 En este punto, la ficción se aleja de la realidad histórica, como acertadamente subraya De Pablo (2017: 293), ya que la posibilidad de que las víctimas se vengaran "Se trata de algo que nunca se ha producido en el País Vasco, pues las víctimas de ETA han vivido su calvario con dignidad e incluso con estoicismo". 
radical y heroico de Martín hacia la asesina de su hermano posibilita un amor surgido en el hervor de la tragedia. La situación de Berta es desesperada en su amor por Martín, a quien ha engañado repetidamente; pero también lo ha hecho con Dubbini y, sin embargo, éste está dispuesto a esperarla a que salga de la cárcel e iniciar una vida con ella. Poco antes del intento de suicidio, Berta escribe una carta a Martín para romper con é ${ }^{10}$ sin que sus palabras expresen realmente sus sentimientos, pues más tarde en el hospital dirá que es el mejor principio que se le ocurre para una relación. La heroicidad que supone un perdón tan radical en la relación de pareja - Martín ha de renunciar a toda venganza e incluso el odio espontáneo hacia la verduga de su hermano - amplifica el discurso humanista y político sobre la violencia terrorista, como se indica más adelante.

La visión de la familia más completa y crítica tiene lugar en Adosados, con unas relaciones presididas por el engaño en una historia que termina confirmando el simulacro de felicidad familiar, la pura impostura o representación de las relaciones entre los esposos — que ya han pasado por una teatralización del placer sexual- $\mathrm{y}$, por extensión, con los hijos. La clausura de este relato resulta enormemente significativa incluso en la puesta en escena, con Paula alejándose de su marido, sentándose en una silla para adquirir el rol de espectadora distanciada y anunciando que seguirá con sus clases de piano (o sea, manteniendo la mentira de la infidelidad con la relación con su amante).

Unos meses después de Adosados se estrena Familia (Fernando León de Aranoa, 1996) donde el simulacro carece de toda máscara, pues se trata de la representación teatral con diversos roles de miembros de una supuesta familia desempeñados por actores contratados al efecto por un hombre que se reserva el papel de padre. Forma parte de un ciclo que, para Ballesteros, "es sintomático de una reconfiguración o un estado de crisis familiar coincidente con la globalidad económica, la redefinición de los hábitos y códigos morales y la masiva integración de la mujer en el ámbito público" (2001: 276-277) ${ }^{11}$.

La filmografía de Mario Camus en los noventa presenta una crítica a la supuesta sociedad del bienestar fruto del crecimiento económico que tiene lugar a finales de la década anterior y hace hincapié en cómo las diferencias socioeconómicas establecen universos de valores éticos, modos de vida y horizontes vitales contrapuestos e irreconciliables. El dinero fácil prima sobre el esfuerzo y el respeto a la profesión; la mentira y la impostura son mecanismos de dominación o enriquecimiento ilegal - $\mathrm{O}$ para el periodismo sensacionalista, medios de manipulación y espectacularidadque revelan la debilidad moral de la sociedad. Se instalan en la sociedad creando víctimas, singularmente de entre los ancianos y en el ámbito de la violencia terrorista, que acaba volviéndose contra los verdugos. Lejos de las convenciones cinematográficas, el amor y la felicidad personal aparecen como resultado gratificante de la trayectoria de personajes honrados y carentes de toda afectación.

10 "No se puede edificar nada permanente sobre un engaño ni sobre una venganza. Si me había dado cuenta de lo que sentía por ti, tenía que haber hecho las cosas de otra manera muy distinta. Pero, al fin y al cabo, Martín, lo nuestro, por encima de mentiras, miserias y torpezas por mi parte no ha podido tener mejor final: antes de dejarte ya te estaba echando de menos. Ahora voy a desaparecer, a alejarme de ti. Tú te vas a ir o te quedas si quieres, pero no nos vamos a ver más."

11 Entre los títulos más significativos indicados por esta autora estarían Celebración (Festen, Thomas Vinterberg,1998), donde la cámara convierte el texto fílmico en una representación, y American Beauty (Sam Mendes, 1999). 


\section{Bibliografía}

Ballesteros, I. (2001). Cine (ins)urgente. Textos filmicos y contextos culturales de la España postfranquista. Madrid: Fundamentos.

Díaz Barrado, M. (2006). La España democrática (1975-2000). Cultura y vida cotidiana. Madrid: Síntesis.

Muñoz, D. (1993). "Entrevista a Mario Camus, director de cine. 'No sé si mi película es valiente o es que el cine español está adormecido"”. La Vanguardia (Barcelona), 9 de septiembre.

Pablo, S. de. (2017). Creadores de Sombras. ETA y el nacionalismo vasco a través del cine. Madrid: Tecnos.

Quílez, R. (2009). "Felipe González y las conversaciones de Argel”. Recuperado de http:// www.elmundo.es/eta/negociaciones/gonzalez.html (Fecha de acceso: 6-7-2018).

Radcliff, P. B. (2018). "De la transición democrática a la consolidación y la crispación: de 1970 hasta hoy”, en José Álvarez Junco y Adrian Shubert (eds.), Nueva historia de la España contemporánea, 1808-2018. Barcelona: Galaxia Gutemberg (epub).

Ruiz, D. (2002). La España democrática (1975-2000). Política y sociedad. Madrid: Síntesis. Sánchez Noriega, J. L. (1997). El cine de Mario Camus: la construcción de la autoría cinematográfica a través del análisis filmico. Madrid: Universidad Complutense (tesis doctorales).

Sánchez Noriega, J. L. (1998). Mario Camus. Madrid: Cátedra.

Sánchez Noriega, J. L. (2007). Mario Camus. Oficio de director. Santander: Valnera.

Sánchez Noriega, J. L. (ed.) (2014). Filmando el cambio social. Las películas de la Transición. Barcelona: Laertes.

Soto Carmona, Á. (2005). Transición y cambio en España, 1975-1996. Madrid: Alianza. 